them. We spend thousands of pounds on education, but to what end ? It is no good pouring money into a school unless we are going to spend money and take time and trouble over the street outside the school; environment will always defeat education. Looking at Britain as an environment, it is important to think of the forces playing on the people personnel managers have to handle: we should think of the way such people are not encouraged to think for themselves at all. The reason why young working people are not showing any sort of enterprise is the recent creation of a complete mass working-class culture.

To keep industry going, we need a fair proportion of young men and women who are individuals with initiative, who think for themselves and have some sense of mental and spiritual development. We should do everything to make that possible, because we do not want our great-grandchildren to be living in an ant-heap and to be indistinguishable from the robots they might be making to serve them.

A valuable feature of the Conference was a number of 'brains trusts' sessions at which experienced personnel officers answered questions on such varied themes as work and health; management training courses; wage differentials ; and discipline and full employment.

T. H. Hawkins

\section{NUTRITION AND THE ALIMENTARY TRACT IN MAN}

$\mathrm{T}$ HE Scottish Group of the Nutrition Society held a conference in Dundee on October 23 on "Disorders of the Alimentary Tract and their Nutritional Effects". In discussing disorders of fat absorption, Dr. J. M. French (Department of Pharmacology, University of Birmingham) said that fat absorption is defective in many clinical conditions, often as part of a generalized absorptive defect. Assessment of the degree of defect of fat absorption cannot be made by microscopic examination or percentage fat in the wet or dry freces, and some type of fat balance must be employed. A continuous study of fat absorption, using the rapid daily fattyacid estimation of Kamer, Huinink and Weijers, is essential if results of treatment or other procedures are to be assessed in a reasonable period of time. The accumulation of data with the same rapidity by the use of balances at intervals is precluded by the great day-to-day variability shown by subjects with defective fat absorption. The continuous method is especially applicable to such problems as the effective replacement therapy of pancreatic insufficiency with various types of pancreatic extract.

Wheat and rye gluten as a causative factor in cœliac disease, originally demonstrated in Holland by Dicke, Weijers and Kamer, has been amply confirmed in Britain. Although many adult cases of idiopathic steatorrhoea have a history of coliac disease in childhood, the response of the adult to a wheat gluten-free diet is disappointing. Five cases of complete recovery have been recorded, however, suggesting that it is the basic factor. Failures may be due to superimposed vitamin deficiency, sensitivity to factors other than wheat and rye protein, or increased bacterial growth in the rich medium provided by the slow absorption of food. Evidence for the latter in tropical sprue has been provided by the use of intestinal chemotherapy.
Specific infection, dietary deficiency and tropical conditions are unsatisfactory as theories for the primary cause of tropical sprue. Considerable evidence has been accumulated to suggest that oxidative rancidity of unsaturated cooking oils may start tropical sprue, the intestine being irritated by some chemical constituent. This evidence is provided by the fact that sprue is rare in tropical countries such as Africa where saturated fats are consumed, but common in India and the Far East where cooking oils, such as rapeseed, sesame and mustard oil, are consumed. The high incidence in India among European and Indian troops during 1942-45 coincided with a change in dietary fat intake both in quantity and type, which would be in conformity with this theory. Experimental support is given by work in rats, which rapidly develop diarrhœea, steatorrhœa, emaciation, anæmia and death, if fed on rancid unsaturated fats.

Dr. R. H. Girdwood (Department of Medicine, Univer'sity of Edinburgh) spoke on the occurrence of vitamin-deficiency conditions related to disorders of the alimentary tract. Conditions that interfere with vitamin intake include destruction of the area of the stomach that secretes the 'intrinsic factor'; rapid passage of vitamins particularly as a result of fistulæ; stagnant or blind loops of small intestine; and disease of the intestine or mesenteric glands.

Clinical impressions of specific vitamin deficiencies are misleading, and biochemical loading tests are not very satisfactory. Nevertheless, a differential urinary folic-acid excretion test is of diagnostic value in showing poor absorption of folic acid in conditions such as idiopathic steatorrhœea. After total or partial gastrectomy operations, or even after a gastro-enterostomy, megaloblastic anæmia may develop ; steatorrhoea may also occur, but serum vitamin $B_{12}$ tests show that the deficiency is of vitamin $\mathrm{B}_{12}$ and not folic acid. Where an anæmia is the result of a stagnant loop, it may not respond to any vitamin therapy, and presumably toxins are being absorbed from the loop.

The interpretation of studies of vitamin balance is complicated by the metabolism of the microbes found in the alimentary tract. Strains have been demonstrated both to synthesize and to absorb such vitamins as cyanocobalamine; their net influence is still uncertain, and may vary in different conditions.

Dr. D. A. K. Black (Department of Medicine, Royal Infirmary, Manchester) discussed the effects of alimentary disease in mineral metabolism. In general, chronic alimentary disease leads to mineral malnutrition as a result of deprivation and malabsorption of food minerals, while in acute catastrophes the loss of alimentary secretions is the predominant feature. Disease of the alimentary tract is the principal cause of potassium depletion, and has been demonstrated in pyloric stenosis, gastro-enteritis, ulcerative colitis and steatorrhcea and even as a consequence of excossive use of laxatives. This may result from deprivation of food intake, which is usually of the order of 100 m.equiv. daily, increased loss in the stools, and loss by vomiting. The potassium content of alimentary secretions is about one-tenth of the sodium content, so that in acute disturbances sodium depletion predominates; nevertheless, significant loss of potassium may occur, in chronic disease partly because colonic absorption of potassium is much less complete than that of sodium and partly because renal loss of potassium is greater than that of sodium when there are comparable body deficits of the two 
ions. The catabolic response to surgery leads to further loss. When potassium has to be given by intravenous injection, it should not be of greater concentration than 40 m.equiv./l.

It is generally agreed that fæcal excretion of iron represents unabsorbed iron. Impaired absorption has been observed in the steatorrhœea syndrome even in patients with neither achlorhydria nor overt diarrhœa. Moderate impairment can often be countered by oral administration of iron salts, but severe cases require intravenous injections.

The pathogenesis of osteomalacia in association with steatorrhoea is complicated. First, the presence of excessive fatty acid in the bowel leads to the formation of calcium soaps the calcium of which is not available for absorption; this can be improved by a low fat diet. Also, vitamin D is poorly absorbed, and further improvement of absorption can be induced by parenteral vitamin $\mathrm{D}$ or very large doses by mouth. The prolonged treatment of peptic ulceration with large amounts of milk and alkalis can lead to calcium intoxication and, in severe cases, renal failure associated with calcification of the renal tubules.

Prof. R. B. Hunter (Department of Pharmacology and Therapeutics, Queen's College, Dundee) reviewed the method of elinical presentation of fifteen cases of idiopathic steatorrhœa recently studied in the Therapeutics Unit, Maryfield Hospital, Dundee. In less than half these cases was diarrhoa the predominant symptom though all complained of tiredness and loss of appetite. The patients learned to control their own diarrhoea by reducing their fat intake. Cases of apparent iron-deficiency anæmia with malabsorption of fat, macrocytic anæmia or megaloblastic anæmias responding to folic acid were shown. Two cases of extreme calcium deficiency were considered in detail, and the problems of finding an effective means of calcium replacement in the face of impaired alimentary absorption were considered.

Food allergy was discussed by Dr. J. A. Milne (Department of Pathology, University of Glasgow), who said that, in order to discuss food allergy, it is necessary to consider first certain basic facts concerning allergic reactions and the immunological basis of allergy. When an antigen first enters the body, it stimulates the formation of specific antibodies. Some of these antibodies tend to persist in their free state in the circulating blood (circulating antibodies), and this would appear to constitute immunity. Others become incorporated into the substance of cells and become 'sessile' antibodies or fixed antibodies, and so the allergic state is established. Why some people develop sessile antibodies and thus become hypersensitive is completely unknown. Various sites may be affected-for example, the nasal mucosa and conjunctiva, the skin, etc.and tissues so affected are known as 'shock organs'. What actually takes place when a tissue containing sessile antibodies comes in contact with its specific antigen is not known. There is considerable experimental and clinical evidence to suggest that histamine or a closely related substance is released.

Proof of the existence of food allergy depends on the demonstration of a cause-and-effect relationship between the ingestion of a given food and the production or accentuation of the patient's symptoms. The use of skin tests, either by the scratch or intradermal technique using concentrated extracts of foods, may occasionally be of help, although on the whole the results tend to be disappointing. For- tunately, many persons with food allergy, as well as having sessile antibodies, have some circulating antibodies. This allows the use of the PrausnitzKustner reaction for diagnostic purposes.

The ideal treatment of food allergy is, of course, the avoidance of the offending food, if this be known. The most widely used drugs at present are the antihistamines, and the results with them other than in papular urticaria in children are rather disappointing. Cortisone and adrenocorticotrophic hormone have been used with good results, although the symptoms tend to recur with increased severity once the drug is withdrawn.

\section{FERROELECTRIC PROPERTIES OF SINGLE CRYSTALS}

A COLLOQUIUM on the ferroelectric properties of single crystals, arranged by the Radio Components Research and Development Committee, was held at the Signals Research and Development Establishment, Christchurch, Hants, during September 16-17. Some sixty scientists attended in response to invitations, the Armed Services establishments, the universities and industry being represented in fairly equal numbers. The Bell Telephone Laboratories, New Jersey, which had supplied a number of large erystals for investigation by British workers, were represented by Dr. B. T. Matthias, who has achieved international reputation in this field. W. Bol and S. Duinker, representing Philips, Eindhoven, were also present.

The first paper, presented by C. F. Oxbrow (Christchureh), was prefaced with a short account of the fundamentals of the structure of barium titanate and their relation to electrical properties. Representative figures measured at Christchurch for the Bell crystals were saturation polarization, $22.5 \mu$ coulombs $/ \mathrm{cm}^{2}$; hysteresis loop area, $1.4 \times 10^{-3}$ joules $/ \mathrm{cm} .^{2}$; permittivity along $c$-axis, 300 at room temperature. The optical properties of the Bell crystals were then described. These crystals, plates $1 \times 1 \times 0.02 \mathrm{~cm}$., had a large area with the optic axis normal to the plate but were crossed by occasional laminar wedges of twinned material inclined at $45^{\circ}$ to the plate. Seen by polarized light, these wedges produced broad interference bands on a uniform background. These twin domains were removed by the application of an electric field. A colour film of this type of domain change was shown, and inferences drawn on domain magnitude and growth. The paper concluded with a description of measurements to determine the refractive index $n_{0}$ accurately, the methods described being particularly applicable to these crystals. A modification of Chaulnes's method led to a value $n_{0}=2 \cdot 49$.

P. Parsons (General Post Office Research Laboratories) exhibited photographs of the Bell crystals showing the erinkling due to the laminar domains as seen by ordinary light, the changes brought about by heating to the Curie point, and the re-establishment of the original domains by an electric field. Electrical measurements were also described. The charge/voltage hysteresis loop was particularly square; the coercive field was of the order of $1.1 \mathrm{kV} . / \mathrm{cm}$. at $50 \mathrm{c} . / \mathrm{s}$. but only $500 \mathrm{~V} . / \mathrm{cm}$. for direct current; in the region of the Curie temperature an electric field gave well-defined double or constricted loops. The behaviour of domain walls is evidently 